\title{
Targeting accuracy of robot-assisted deep brain stimulation surgery in childhood-onset dystonia: a single-center prospective cohort analysis of $\mathbf{4 5}$ consecutive cases
}

\author{
*Luciano Furlanetti, MD, PhD, ${ }^{1,4}$ Jonathan Ellenbogen, MD, ${ }^{3}$ Hortensia Gimeno, PhD, ${ }^{2,4}$ \\ Laura Ainaga, MSc, ${ }^{2,4}$ Vijay Narbad, MD, ${ }^{1}$ Harutomo Hasegawa, FRCS,,4 \\ Jean-Pierre Lin, MD, PhD, ${ }^{2,4}$ Keyoumars Ashkan, MD, ${ }^{1,4}$ and Richard Selway, MD ${ }^{1,4}$
}

'Department of Neurosurgery, King's College Hospital NHS Foundation Trust, London; ${ }^{2}$ Complex Motor Disorders Service, Evelina London Children's Hospital, Guy's and St. Thomas' NHS Foundation Trust, London; ${ }^{3}$ Alder Hey Children's Hospital NHS Foundation Trust, Liverpool; and 'King's Health Partners Academic Health Sciences Centre, London, United Kingdom

OBJECTIVE Deep brain stimulation (DBS) is an established treatment for pediatric dystonia. The accuracy of electrode implantation is multifactorial and remains a challenge in this age group, mainly due to smaller anatomical targets in very young patients compared to adults, and also due to anatomical abnormalities frequently associated with some etiologies of dystonia. Data on the accuracy of robot-assisted DBS surgery in children are limited. The aim of the current paper was to assess the accuracy of robot-assisted implantation of DBS leads in a series of patients with childhood-onset dystonia.

METHODS Forty-five children with dystonia undergoing implantation of DBS leads under general anesthesia between 2017 and 2019 were included. Robot-assisted stereotactic implantation of the DBS leads was performed. The final position of the electrodes was verified with an intraoperative 3D scanner $(\mathrm{O}$-arm). Coordinates of the planned electrode target and actual electrode position were obtained and compared, looking at the radial error, depth error, absolute error, and directional error, as well as the euclidean distance. Functional assessment data prospectively collected by a multidisciplinary pediatric complex motor disorders team were analyzed with regard to motor skills, individualized goal achievement, and patients' and caregivers' expectations.

RESULTS A total of 90 DBS electrodes were implanted and $48.5 \%$ of the patients were female. The mean age was 11.0 \pm 0.6 years (range $3-18$ years). All patients received bilateral DBS electrodes into the globus pallidus internus. The median absolute errors in $x-, y-$, and z-axes were $0.85 \mathrm{~mm}$ (range $0.00-3.25 \mathrm{~mm}$ ), $0.75 \mathrm{~mm}$ (range $0.05-2.45 \mathrm{~mm}$ ), and 0.75 $\mathrm{mm}$ (range $0.00-3.50 \mathrm{~mm}$ ), respectively. The median euclidean distance from the target to the actual electrode position was $1.69 \pm 0.92 \mathrm{~mm}$, and the median radial error was $1.21 \pm 0.79$. The robot-assisted technique was easily integrated into the authors' surgical practice, improving accuracy and efficiency, and reducing surgical time significantly along the learning curve. No major perioperative complications occurred.

CONCLUSIONS Robot-assisted stereotactic implantation of DBS electrodes in the pediatric age group is a safe and accurate surgical method. Greater accuracy was present in this cohort in comparison to previous studies in which conventional stereotactic frame-based techniques were used. Robotic DBS surgery and neuroradiological advances may result in further improvement in surgical targeting and, consequently, in better clinical outcome in the pediatric population. https://thejns.org/doi/abs/10.3171/2020.10.PEDS20633

KEYWORDS dystonia; deep brain stimulation; robot-assisted surgery; accuracy; pediatric; functional neurosurgery

ABBREVIATIONS BFMDRS = Burke-Fahn-Marsden Dystonia Rating Scale; BFMDRS-D = BFMDRS-disability; BFMDRS-M = BFMDRS-movement; COPM = Canadian Occupational Performance Measure; COPM-P = COPM-performance; COPM-S = COPM-satisfaction; DBS = deep brain stimulation; ED = euclidean distance; FOV = field of view; $\mathrm{GPi}$ = globus pallidus internus; MACS = Manual Ability Classification System; MA-2 = Melbourne Assessment 2 of Unilateral Upper Limb Function; RE = radial error; $\mathrm{ROM}=$ range of motion.

SUBMITTED July 17, 2020. ACCEPTED October 6, 2020 .

INCLUDE WHEN CITING Published online April 16, 2021; DOI: 10.3171/2020.10.PEDS20633.

${ }^{*}$ K.A. and R.S. share senior authorship of this work. 
$\mathrm{D}$ YSTONIA syndromes may be of genetic origin or secondary to diverse brain/basal ganglia insults. ${ }^{1}$ Although the underlying pathophysiological mechanisms of dystonia are not well understood, current consensus points to functional disorganization in the thalamocortical-basal ganglia neural loop. ${ }^{1}$ Clinical and surgical management of dystonia has evolved substantially during the last decades. Stereotactic techniques in the mid-20th century included pallidotomy, but mainly thalamotomies, to control dystonic movement in adults. ${ }^{2}$ Following the introduction of deep brain stimulation (DBS) for essential tremor and Parkinson's disease in the early 1990s, the globus pallidus internus (GPi) emerged as the main DBS target for dystonia both in adults and in pediatric patients. ${ }^{3-5}$ The most dramatic improvements have been documented in inherited dystonia, mainly in cases with a mutation in the DYT1 gene. ${ }^{6}$ However, other forms of the disease, such as tardive dystonia, have often shown a major benefit. ${ }^{7,8}$ GPi DBS is currently an established management option for children with dystonia. ${ }^{9,10}$

The success of DBS surgery is multifactorial, but the most prominent determinants are the selection of the right candidates and the accuracy of electrode placement- the latter is crucial for optimal clinical responses and to avoid stimulation-induced side effects. ${ }^{11}$ In line with this, stereotactic inaccuracy has always been a concern in functional neurosurgery and is a summation of inaccuracies in imaging resolution and fusion algorithms, frame registration, and procedural mechanics. Currently, diverse methods for stereotactic implantation of DBS electrodes are available, from standard frame-based techniques to frameless devices and robot-assisted surgery. The integration of robotics and intraoperative imaging has provided further refinement of the technique, increasing performance and minimizing the number of surgical steps prone to human error. ${ }^{12}$ During the last 30 years, diverse robotic systems have been developed for stereotactic neurosurgery and experience has accumulated with several clinical indications, i.e., tumor biopsies, stereoelectroencephalography, radiosurgery, and DBS surgery, although almost exclusively in adult patients.

In the current study, we present a single-center consecutive series of robot-assisted stereotactic implantations of DBS electrodes within the GPi in patients with childhoodonset dystonia. The main goals of this work were to assess the safety and feasibility of robot-assisted DBS surgery, as well as to evaluate the application accuracy of this method and the clinical outcome in pediatric patients.

\section{Methods \\ Patient Selection}

Pediatric patients with a diagnosis of medically intractable dystonia were prospectively included in the study. Routine preoperative evaluation included detailed neurological, neurophysiological, and neuroimaging review, prior to discussion by the multidisciplinary team. Patients with indications for neurosurgical management were assessed and received DBS implants in the same institution between 2017 and 2019. Clinical outcome and perioperative complications were prospectively recorded. This study was approved by our institution's research advisory group, and all procedures followed the Declaration of Helsinki, 1975, as revised in 2013.

\section{Surgical Procedure}

Standard MRI sequences were obtained on 1.5-T General Electric or Siemens scanners during the preoperative assessment. ${ }^{19}$ The MRI protocol included a T1-weighted 3D inversion recovery prepared fast spoiled gradient echo volume, with inversion time $450 \mathrm{msec}$, TE $3.8 \mathrm{msec}$, TR $9.5 \mathrm{msec}$, flip angle $25^{\circ}$, field of view (FOV) $240 \mathrm{~mm}$, matrix $256 \times 256$, slice thickness $1.4 \mathrm{~mm}$, and receiver bandwidth $\pm 23 \mathrm{kHz}$, resulting in a final voxel resolution of $0.94 \times 0.94 \times 0.7 \mathrm{~mm}^{3}$. The extreme posteroventral aspect of the GPi was directly targeted, following visual recognition of its boundaries on a proton density-weighted fast spin echo sequence, ${ }^{19}$ with TE $11 \mathrm{msec}$, TR $4 \mathrm{msec}$, flip angle $90^{\circ}$, FOV $250 \mathrm{~mm}$, receiver bandwidth $\pm 21 \mathrm{kHz}$, acquisition matrix $256 \times 256$, reconstruction matrix $512 \times$ 512 , and slice thickness $2 \mathrm{~mm}$, resulting in a final reconstructed voxel resolution of $0.5 \times 0.5 \times 2 \mathrm{~mm}^{3}$. The center of the posterior third quarter of the GPi was targeted, just above the outer optic tract, as previously described. ${ }^{4}$

On the day of surgery, a Leksell $\mathrm{G}$ frame (Elekta) is fixed to the patient's head under general anesthesia. The operating table is leveled with the headrest platform and attached to the neuromate robot (Renishaw). From this stage on, because the head of the patient is docked on the robot and the rest of the body is on the operating table, neither the base of the robot nor the operating table can be moved, otherwise risking an injury to the cervical spine. Next, the neurolocate registration module is attached to the articulated arm of the neuromate robot, which is moved to registration position. The $\mathrm{O}$-arm (Medtronic Inc.) is moved over the patient and aligned for acquisition of intraoperative stereotactic imaging. O-arm scans (high spatial resolution volumetric bone window data set, matrix $512 \times 512$, FOV $210 \mathrm{~mm}$, slice thickness $0.8 \mathrm{~mm}$, voltage $95 \mathrm{kV}$, and charge $20 \mathrm{~mA}$ ) are transferred to the neuroinspire planning software (Renishaw) and stereotactic coordinates of the targets are acquired by merging the data set with the planning MRI scan.

The accuracy of the resulting patient localization is verified prior to conducting surgery; in the verification process, test trajectories to external features of the frame of the patient are targeted. The patient is then prepared and draped in standard fashion. Incision and burr holes are made based on our robotically aligned trajectories. Once the burr holes have been prepared and the dura mater opened, the neuroguide tube (Renishaw) is inserted in the selected trajectory and self-attached to the burr hole. A quadripolar DBS lead (3389, Medtronic Inc.) is inserted through the guide tube down to the planned target and secured on the skull surface. The target is routinely set at the middle of the lowest contact. The same procedure is repeated on the contralateral side. Surgery is performed in two stages on the same day, i.e., insertion of the intracranial leads, followed by placement of extensions and an implantable pulse generator (Activa RC, Medtronic Inc.). Intraoperative microelectrode recording was not used in this cohort. An intraoperative final O-arm scan is performed to verify the position of the DBS electrodes. All 
patients are reviewed on a monthly basis for 3 postoperative months and then every 3 months thereafter in the 1st year. The following settings were routinely implemented on the 1st postoperative day: monopolar stimulation with $130 \mathrm{~Hz}$, pulse width $450 \mu \mathrm{sec}$, and initial voltage $0.5 \mathrm{~V}$, which was adapted individually according to the patient's clinical response during the follow-up period.

\section{Outcome Assessment}

Outcome scales used in the preoperative and postoperative evaluation of patients included assessments of 1) dystonia severity; 2) goal attainment; and 3) upper-limb motor function. The Burke-Fahn-Marsden Dystonia Rating Scale-movement (BFMDRS-M) and BFMDRSdisability (BFMDRS-D) were used to monitor progress with dystonia reduction. ${ }^{20}$ The overall percentage change in BFMDRS scores was calculated using the following equation: [(Baseline score - Postoperative score/Baseline score) $\times 100$ ]. Goal attainment was assessed using the $\mathrm{Ca}-$ nadian Occupational Performance Measure (COPM), a patient-reported outcome measuring patient and caregiver performance (COPM-P) and satisfaction (COPM-S) with self-selected personalized functional goals. ${ }^{21}$ In line with previous publications, a change of 2 points in the postoperative COPM assessment was deemed clinically significant. ${ }^{21}$ Changes in upper-limb function were evaluated using the Melbourne Assessment 2 of Unilateral Upper Limb Function (MA-2). ${ }^{22}$ The MA-2 scale evaluates improvement in dexterity, range of motion (ROM), fluency, and accuracy of the use of the upper limbs. ${ }^{23}$ Both dominant and nondominant upper limbs were assessed for postoperative functional improvement. A change of 11 points in MA-2 was considered significant. ${ }^{22}$ Manual function severity was also categorized using the Manual Ability Classification System (MACS). ${ }^{23}$

\section{Accuracy of Electrode Placement and Data Collection}

The intraoperative $\mathrm{O}$-arm scans obtained for verification of the position of the DBS leads were merged to preoperative planning MRI on neuroinspire. The final position of the electrodes was compared to the preoperative planning. Coordinates of the planned target and actual position of the center of the lowest DBS contact were obtained and compared, looking at the radial error (RE); depth error; and absolute and directional errors in the $\mathrm{X}$-, $\mathrm{y}$-, and z-axes as well as the euclidean distance (ED), as described elsewhere. ${ }^{13,14,24}$ The data were entered onto a Microsoft Excel worksheet and statistically analyzed using the SPSS version 24 software (IBM Corp.). One-way and 2-way ANOVAs were used to compare variables with normal distribution and effect across groups. The Newman-Keuls test was applied post hoc when a main group effect was detected. A nonparametric test (Wilcoxon signed-rank test) was applied for variables that did not follow a normal distribution. Comparisons with a $\mathrm{p}$ value less than 0.05 were considered significant.

\section{Results}

\section{Demographic Findings}

A total of 90 DBS electrodes were implanted and 51.1\% of the patients were female. The mean age was $11.0 \pm 0.6$ years (range 3-18 years). All patients received bilateral DBS electrodes into the GPi. The mean follow-up time was $23.0 \pm 9.3$ months. Demographic and clinical details are summarized in Table 1.

\section{DBS Workflow}

After an initial training and habituation period, the robot-assisted stereotactic technique coupled with intraoperative O-arm imaging was fully integrated into our DBS routine, leading to a more efficient surgical workflow along the learning curve. The mean surgical time for bilateral GPi DBS in this cohort was $156.9 \pm 35.1 \mathrm{~min}-$ utes. No major perioperative complications occurred. Of 45 patients, $2(4.4 \%)$ presented with wound site infection, for which the implants were temporarily removed, and 3 $(6.6 \%)$ other patients experienced migration of one of the DBS leads, which were revised accordingly.

\section{Assessment of Accuracy of Robot-Assisted Electrode Placement}

The median absolute errors in the $\mathrm{x}-, \mathrm{y}-$, and $\mathrm{z}$-axes were $0.85 \mathrm{~mm}$ (range $0.00-3.25 \mathrm{~mm}$ ), $0.75 \mathrm{~mm}$ (range $0.05-2.45 \mathrm{~mm}$ ), and $0.75 \mathrm{~mm}$ (range 0.00-3.50 $\mathrm{mm}$ ), respectively. The median ED was $1.69 \pm 0.92 \mathrm{~mm}$ (range 0.46-4.42 mm), and the median RE was $1.21 \pm 0.79 \mathrm{~mm}$ (range 0.17-3.49 $\mathrm{mm}$ ). There was no significant difference between right- and left-sided electrodes regarding the RE $(\mathrm{p}=0.19)$ nor the ED $(\mathrm{p}=0.21)$. Relative differences in electrode position from the target are represented in Fig. 1. The overall median directional error in the $\mathrm{x}, \mathrm{y}$, and $\mathrm{z}$ planes was $0.2 \mathrm{~mm}$. No statistically significant trend toward deviations in a specific direction was observed $(\mathrm{p}>$ $0.05)$. A total of $7(7.7 \%)$ of the 90 electrodes were readjusted following the intraoperative scan, based on an ED greater than $2 \mathrm{~mm}$ (mean $3.0 \pm 0.6 \mathrm{~mm}$ ).

In order to better understand the impact of the learning curve and refinement of technical aspects of the procedure on accuracy of electrode placement, variables were analyzed and compared across the first 3 years of our experience. When looking at the evolution of accuracy and precision with time, we observed a statistically significant reduction of the absolute error in the $\mathrm{x}$-axis $(1.18,1.08$, and $0.48 \mathrm{~mm}$ ) [groups $\mathrm{F}(2,42)=5.0, \mathrm{p}=0.01$ ] and $\mathrm{z}$-axis $(1.15,1.05$, and $0.54 \mathrm{~mm})$ [groups $\mathrm{F}(2,42)=3.2, \mathrm{p}=0.05$ ] and, consequently, an improvement of the mean RE (1.47, 1.56 , and $0.83 \mathrm{~mm}$ ) [groups $\mathrm{F}(2,42)=5.0, \mathrm{p}=0.01$ ] and of the $\operatorname{ED}(2.01,2.02$, and $1.04 \mathrm{~mm})$ [groups $\mathrm{F}(2,42)=6.9$, $\mathrm{p}=0.02]$ between the planned target and final position of the DBS lead (Fig. 2). A positive correlation between the RE and ED was observed $(r=0.84, p<0.001)$. Alongside that, an improvement in surgical efficiency was noted, with reduction of total surgical time [groups $\mathrm{F}(2,42)=$ $12.0, \mathrm{p}=0.001]$ and complication rates. The incidence of postoperative complications dramatically decreased over time-i.e., 21.4\% (3/14) in the 1st year, $12.5 \%(2 / 16)$ in the 2nd year, and no complications in the last year $(0 / 15)$ - at a minimum follow-up time of 7 months postsurgery. Furthermore, longer surgical times $(205.4 \pm 39.6$ minutes vs $150.85 \pm 29.9$ minutes, $\mathrm{p}=0.001$ ) and EDs greater than 
TABLE 1. Demographics, application accuracy, and follow-up in 45 patients with dystonia who underwent DBS

\begin{tabular}{|c|c|c|c|c|c|c|c|c|c|}
\hline \multirow[b]{2}{*}{$\begin{array}{l}\text { Case } \\
\text { No. }\end{array}$} & \multicolumn{5}{|c|}{ Demographics } & \multicolumn{2}{|c|}{ Application Accuracy } & \multicolumn{2}{|l|}{$\mathrm{FU}$} \\
\hline & Sex & $\begin{array}{l}\text { Age (yrs) } \\
\text { at Op }\end{array}$ & $\begin{array}{l}\% \text { of Life Lived } \\
\text { w/ Dystonia }\end{array}$ & $\begin{array}{l}\text { Type of } \\
\text { Dystonia }\end{array}$ & $\begin{array}{l}\text { Underlying } \\
\text { Diagnosis }\end{array}$ & $\begin{array}{l}\text { Median } \\
\text { ED (mm) }\end{array}$ & $\begin{array}{l}\text { Median } \\
\text { RE }(m m)\end{array}$ & Complications & $\begin{array}{l}\text { Time } \\
\text { (mos) }\end{array}$ \\
\hline 1 & $\mathrm{~F}$ & 9 & 44 & Inherited & DYT1 & 1.42 & 1.21 & No & 27 \\
\hline 2 & $\mathrm{~F}$ & 15 & 99 & Acquired & $\mathrm{CP}$ & 1.55 & 1.00 & No & 27 \\
\hline 3 & $\mathrm{~F}$ & 16 & 97 & Acquired & $\mathrm{CP}$ & 1.03 & 0.81 & No & 28 \\
\hline 4 & M & 11 & 95 & Inherited & Lesch-Nyhan & 3.83 & 1.80 & Elect migration & 29 \\
\hline 5 & $\mathrm{~F}$ & 10 & 55 & Inherited & DYT6 & 1.95 & 1.77 & No & 30 \\
\hline 6 & M & 16 & 96 & Acquired & GA1 & 2.69 & 2.10 & No & 31 \\
\hline 7 & M & 10 & 15 & Inherited & DYT1 & 1.71 & 1.56 & No & 31 \\
\hline 8 & M & 17 & 96 & Acquired & $\mathrm{CP}$ & 1.04 & 0.82 & No & 32 \\
\hline 9 & $\mathrm{~F}$ & 18 & 50 & Inherited & PKAN & 3.14 & 2.41 & Infection & 33 \\
\hline 10 & $\mathrm{~F}$ & 8 & 63 & Inherited & KMT2B & 1.89 & 1.83 & Elect migration & 33 \\
\hline 11 & $\mathrm{~F}$ & 8 & 81 & Acquired & Metabolic-non-GA1 & 2.61 & 1.67 & No & 33 \\
\hline 12 & M & 8 & 97 & Idiopathic & Idiopathic & 4.42 & 3.24 & Elect migration & 34 \\
\hline 13 & $\mathrm{~F}$ & 10 & 95 & Acquired & $\mathrm{CP}$ & 2.03 & 1.76 & No & 35 \\
\hline 14 & $\mathrm{~F}$ & 18 & 97 & Acquired & $\mathrm{CP}$ & 2.39 & 0.36 & No & 36 \\
\hline 15 & $\mathrm{~F}$ & 12 & 99 & Acquired & $\mathrm{CP}$ & 1.43 & 0.97 & No & 35 \\
\hline 16 & M & 14 & 50 & Inherited & DYT6 & 1.27 & 0.65 & No & 26 \\
\hline 17 & M & 6 & 96 & Inherited & GNAO1 & 1.97 & 1.66 & No & 25 \\
\hline 18 & M & 6 & 96 & Acquired & $\mathrm{CP}$ & 2.25 & 1.31 & Infection & 25 \\
\hline 19 & M & 11 & 99 & Acquired & $\mathrm{CP}$ & 1.88 & 1.39 & No & 24 \\
\hline 20 & $M$ & 10 & 99 & Acquired & $\mathrm{CP}$ & 2.94 & 2.58 & No & 24 \\
\hline 21 & $F$ & 12 & 58 & Inherited & DYT1 & 1.78 & 1.11 & No & 23 \\
\hline 22 & M & 9 & 99 & Acquired & $\mathrm{CP}$ & 2.58 & 2.36 & No & 21 \\
\hline 23 & $\mathrm{~F}$ & 11 & 82 & Inherited & POLR1C & 1.98 & 1.55 & No & 21 \\
\hline 24 & $\mathrm{~F}$ & 11 & 94 & Acquired & GA1 & 1.87 & 1.43 & No & 20 \\
\hline 25 & $\mathrm{~F}$ & 12 & 63 & Inherited & PRRT2 & 1.94 & 1.84 & No & 19 \\
\hline 26 & $M$ & 7 & NA & Acquired & GA1 & 2.78 & 2.25 & No & 19 \\
\hline 27 & M & 11 & 27 & Inherited & DYT1 & 1.94 & 1.51 & No & 18 \\
\hline 28 & M & 6 & 33 & Inherited & PKAN & 2.46 & 2.34 & No & 17 \\
\hline 29 & $F$ & 15 & 87 & Acquired & GA1 & 1.74 & 1.63 & No & 17 \\
\hline 30 & $M$ & 18 & 83 & Idiopathic & Idiopathic & 1.57 & 1.11 & No & 16 \\
\hline 31 & $M$ & 13 & 96 & Inherited & KMT2B & 2.43 & 2.40 & No & 16 \\
\hline 32 & M & 8 & 13 & Inherited & DYT1 & 1.32 & 0.96 & No & 15 \\
\hline 33 & $\mathrm{~F}$ & 15 & 87 & Inherited & KMT2B & 1.27 & 0.65 & No & 41 \\
\hline 34 & $\mathrm{~F}$ & 10 & 70 & Inherited & KMT2B & 0.55 & 0.50 & No & 33 \\
\hline 35 & $\mathrm{~F}$ & 10 & 78 & Inherited & KMT2B & 1.07 & 1.04 & No & 39 \\
\hline 36 & M & 6 & 98 & Acquired & $\mathrm{CP}$ & 1.09 & 0.35 & No & 13 \\
\hline 37 & $F$ & 3 & NA & Inherited & GNA01 & 1.08 & 0.89 & No & 13 \\
\hline 38 & $\mathrm{~F}$ & 6 & NA & Idiopathic & Idiopathic & 0.63 & 0.47 & No & 10 \\
\hline 39 & $\mathrm{~F}$ & 15 & NA & Inherited & MECP2 & 0.99 & 0.96 & No & 11 \\
\hline 40 & $\mathrm{~F}$ & 8 & NA & Acquired & $\mathrm{CP}$ & 0.50 & 0.36 & No & 10 \\
\hline 41 & M & 16 & NA & Inherited & KMT2B & 0.95 & 0.68 & No & 9 \\
\hline 42 & $M$ & 10 & 60 & Inherited & DYT11 & 1.20 & 1.08 & No & 7 \\
\hline 43 & $F$ & 13 & 88 & Inherited & DYT11 & 1.37 & 1.18 & No & 9 \\
\hline 44 & M & 8 & 83 & Inherited & KMT2B & 1.00 & 0.83 & No & 10 \\
\hline 45 & M & 10 & 60 & Inherited & KMT2B & 1.62 & 1.51 & No & 11 \\
\hline
\end{tabular}

$\mathrm{CP}=$ cerebral palsy; Elect = electrode; FU = follow-up; GA1 = glutaric aciduria type 1; NA = not available; $\mathrm{PKAN}=$ pantothenate kinase-associated neurodegeneration. 

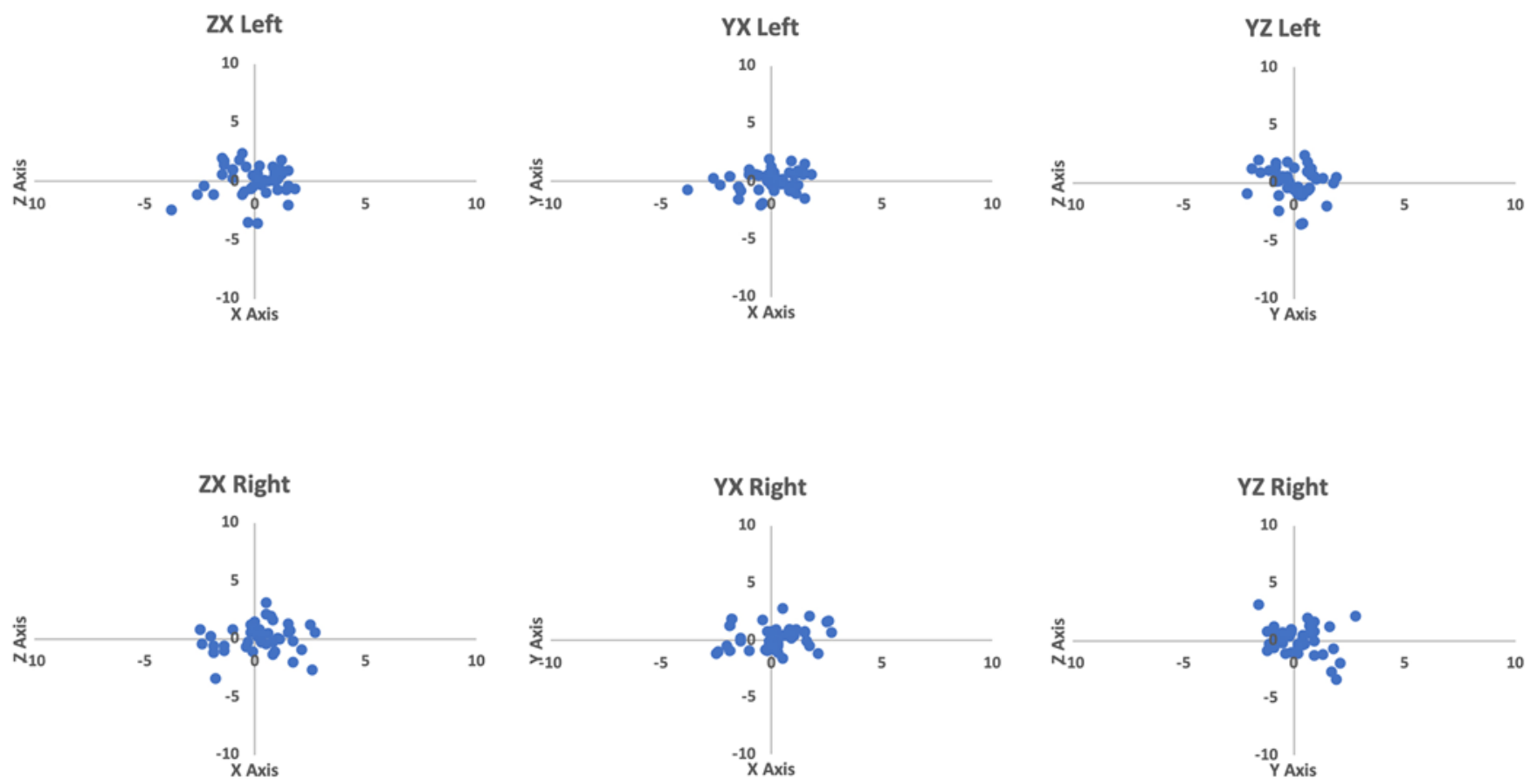

FIG. 1. Scatterplots showing deviation (in millimeters) of lead tip from target in the $x, y$, and $z$ planes for the right and left sides. No significant difference between right- and left-sided electrodes was detected. The overall median directional error in the $x-, y-$, and $z$-axes was $0.2 \mathrm{~mm}$. No statistically significant trend toward deviations in a specific direction was observed $(p>0.05)$. Figure is available in color online only.

$2 \mathrm{~mm}(\mathrm{p}=0.008)$ were associated with the occurrence of perioperative complications and the need for revision surgery $(\mathrm{p}<0.001)$.

The statistical analysis taking into account other variables showed no statistically significant difference in accuracy across sex (ED: male $2.04 \pm 0.92$, female $1.57 \pm$ $0.65, \mathrm{p}=0.055$; RD: male $1.56 \pm 0.74$, female $1.19 \pm 0.55$, $\mathrm{p}=0.06)$; age groups $(\mathrm{p}=0.8)$; or etiology of dystonia $(\mathrm{p}$ $=0.8)$ in this cohort.

\section{Clinical Assessment of Postoperative Outcome}

Table 2 summarizes the available outcome data for each patient.

Thirty-seven (82.2\%) patients completed a minimum 12 months of follow-up. In this heterogeneous cohort of patients, at least 15 different underlying etiologies of dystonia were identified, whereas $25(55 \%)$ children were diagnosed with inherited forms of dystonia. The median proportion of life lived with dystonia at the time of DBS surgery was $86 \%$ (range 13\%-99\%). The mean percentage change in BFMDRS across all patients at the 1-year follow-up was $10.0 \% \pm 22.6 \%$ (range $-30.4 \%$ to $66.9 \%$ ). Patients diagnosed with genetic syndromes, such as DYT1 and DYT6 mutations, had significantly better outcome than those with acquired forms of dystonia [groups $\mathrm{F}(1,19)$ $=8.5, \mathrm{p}=0.009]$. Because BFMDRS may not accurately capture changes in motor function following DBS surgery for dystonia in children, ${ }^{21,23}$ other assessment tools were also used to evaluate functional recovery or acquisition of upper-limb motor skills.

\section{Evaluation of Postoperative Goal Achievement and Upper-Limb Function}

Goal achievement evaluation was performed using the COPM assessment tool. ${ }^{21}$ An overall significant improvement in COPM-P and COPM-S related to DBS therapy was observed among both primary and acquired forms of dystonia, with no statistical differences between groups ( $p$ $=0.1$ ). Changes in upper-limb function were evaluated using the MA-2 scale.22 Percentage changes in upper-limb ROM, accuracy, dexterity, and fluency were evaluated. Patients with genetic forms of dystonia presented a significantly better improvement in MA-2-fluency $(14.8 \pm 12.2)$ than their counterparts with acquired dystonic syndromes $(2.7 \pm 6.9)$ [groups $\mathrm{F}(1,17)=6.6, \mathrm{p}=0.01]$. Furthermore, statistical analysis revealed that the proportion of life lived with dystonia was inversely correlated with clinical improvement in BFMDRS $(\mathrm{r}=-0.52, \mathrm{p}=0.01)$ and in functional skills of the dominant hand (MA-2-fluency: $r$ $=-0.55, p=0.01$ ). Increasing age at time of DBS surgery was also inversely correlated with improvement of upperlimb motor skills (MA-2-fluency: $r=-0.51, p=0.02$ ).

Interestingly, percentage improvement depicted in BFMDRS strongly correlated with the patient's performance (COPM-P: $\mathrm{r}=0.66, \mathrm{p}=0.14$ ) and satisfaction (COPM-S: $\mathrm{r}=0.56, \mathrm{p}=0.04)$ concerning goal achievement at the 1-year follow-up. A positive correlation between BFMDRS and improvement in MA-2-ROM of the dominant hand was also observed $(\mathrm{r}=0.63, \mathrm{p}=0.01)$. After adjusting for expected differences in response to GPi DBS due to a variety of etiologies and backgrounds 


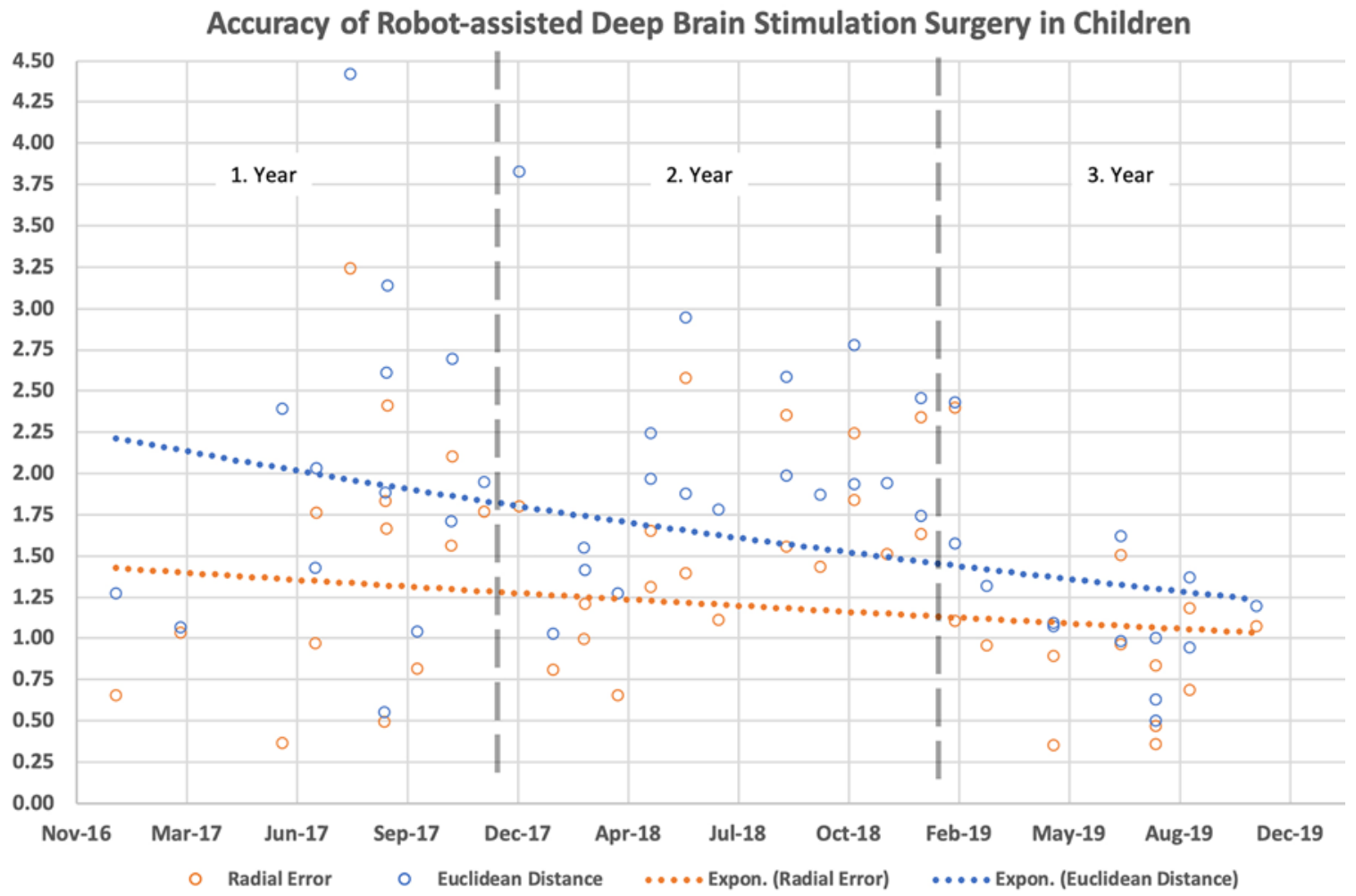

FIG. 2. Scatterplots showing evolution of application accuracy across time. A reduction of the absolute error in the $x$-axis (1.18, 1.08 , and $0.48 \mathrm{~mm})$ and in the $z$-axis $(1.15,1.05$, and $0.54 \mathrm{~mm})$ led to a significant reduction of the mean $\operatorname{RE}(1.47,1.56$, and 0.83 $\mathrm{mm})$ and of the $\operatorname{ED}(2.01,2.02$, and $1.04 \mathrm{~mm})(\mathrm{p}=0.02)$ between the planned target and final position of the DBS lead. Figure is available in color online only.

causing dystonia, no correlation between the accuracy of electrode placement and outcome could be determined in this cohort.

Further analysis taking into consideration hand dominance and the preoperative MACS grade provided interesting results. Patients with better preoperative manual function (MACS grades I-III) were more likely to successfully achieve self-selected personalized functional goals (assessed using COPM) than patients with unsatisfactory function (MACS grades IV and V) at the 1-year follow-up $(\mathrm{p}=0.002)$. Moreover, there was no difference in postoperative improvement of upper-limb function assessed with MA-2 between right- and left-handed patients. However, a statistically significant difference was noted concerning MA-2 changes in the right and left nondominant upperlimb assessment, where the right nondominant upper-limb function improved to a better extent than the left [ROM: $\mathrm{F}(2,13)=2.2, \mathrm{p}=0.02$; fluency: $\mathrm{F}(2,13)=2.9, \mathrm{p}=0.05]$.

\section{Discussion}

Following the first reports of the Montpellier group $3,4,6$ on the successful management of children with dystonia by bilateral neuromodulation of the GPi, growing evidence during the last 20 years has supported and expanded the application of DBS in pediatric movement disorders. ${ }^{5,7,8}$, ${ }^{25,26}$ This prospective clinical study aimed to evaluate the feasibility of robot-assisted stereotactic DBS surgery in a cohort of pediatric patients with dystonia. Safety and application accuracy as well as preliminary clinical outcomes were assessed. Other groups have previously reported encouraging results. ${ }^{27,28}$ However, to the best of our knowledge, this is the largest single-center case series of robot-assisted DBS for the treatment of childhood-onset hyperkinetic movement disorders, including dystonia, in the pediatric population.

The findings showed that following an initial period of training of the operating theater staff and familiarization with the workflow, the robot-assisted technique was easily integrated into our surgical practice, improving accuracy and efficiency, and reducing surgical time significantly along the learning curve.

Interestingly, the application accuracy of the robot-assisted technique was better when compared with a previously published cohort of 42 children with dystonia, operated on by the same group, using a standard approach with the Leksell $\mathrm{G}$ frame and intraoperative microelectrode recordings..$^{29}$ The median euclidean displacement of the standard frame-based technique in that study was 2.04 $\mathrm{mm}$ on the left and $2.45 \mathrm{~mm}$ on the right, ${ }^{29}$ whereas the robot-assisted technology allowed a significant reduction of this error to $1.68 \mathrm{~mm}$ on the left and $1.70 \mathrm{~mm}$ on the right side. Moreover, a further refinement of the robot-assisted technique, with the introduction of a more stable $4.8-\mathrm{mm}$ tailored drill bit, correctly attached to the robotic arm, decreased the insertion RE significantly, reaching a median ED of $1.04 \mathrm{~mm}$ and a median RE of $0.83 \mathrm{~mm}$ in the last period studied. The previously used hands-free technique 


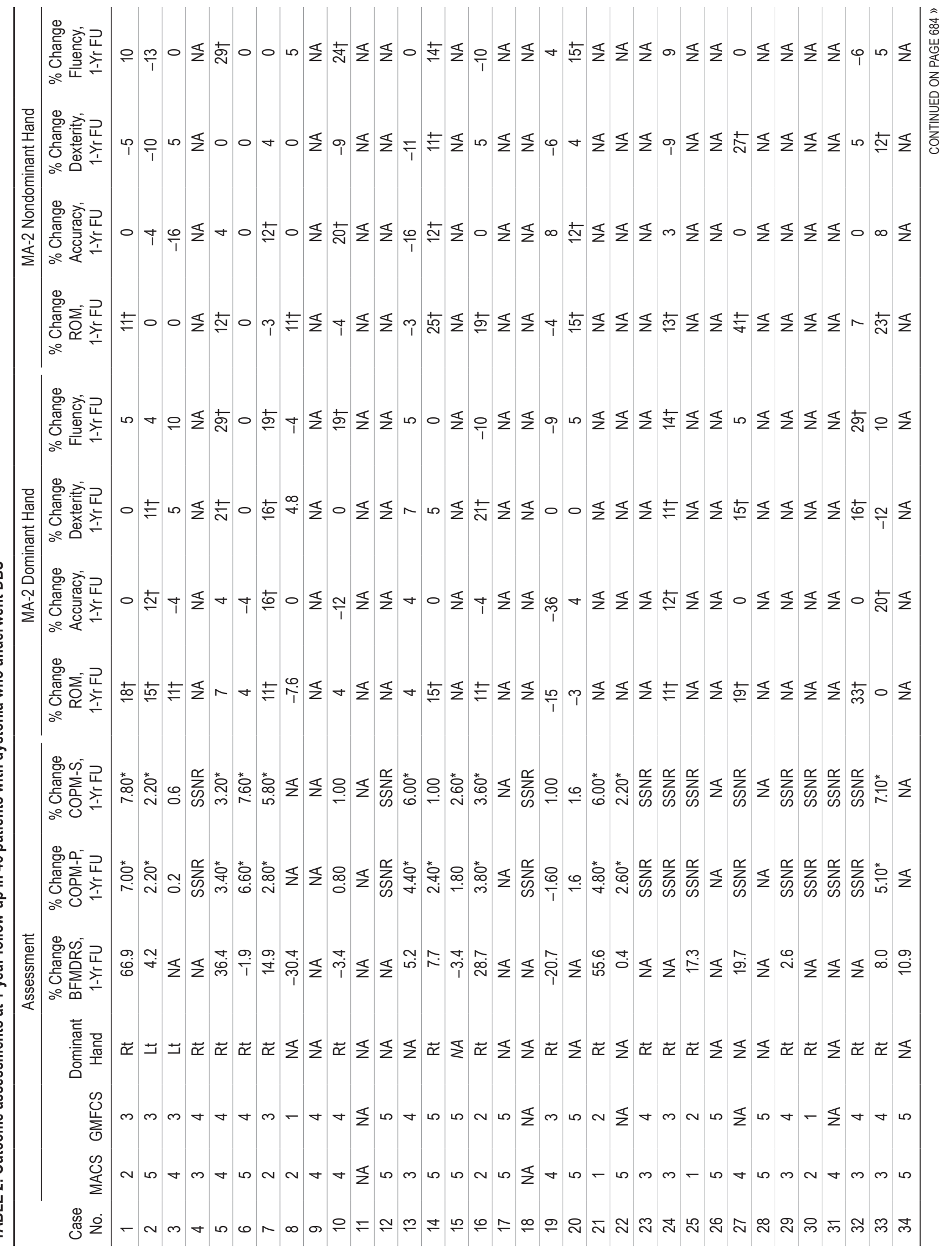




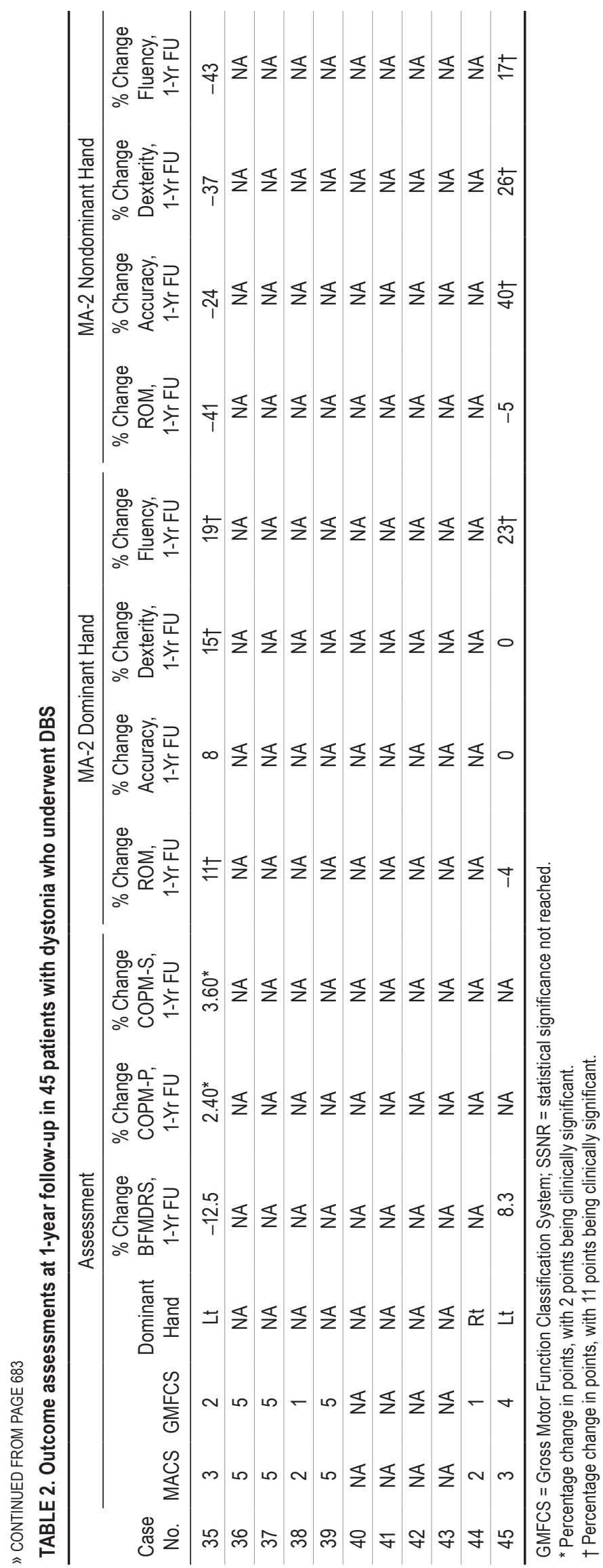

for placement of mini-burr holes on the skull was probably prone to small imperfections such as residual bony or dural edges, which may have caused deviation of the electrode from the planned trajectory in some cases. The improvement of targeting accuracy in the present cohort was mainly due to statistically significant reduction of the absolute error in the $\mathrm{x}$-axis (from initial mean $1.18 \mathrm{~mm}$ to $0.48 \mathrm{~mm}$ ) and in the $\mathrm{z}$-axis (from $1.15 \mathrm{~mm}$ to $0.54 \mathrm{~mm}$ ). Importantly, this prospective study represented our first experience with the use of the robot-assisted technique for DBS surgery in children. Nevertheless, in line with the current literature, the application accuracy of robotic surgery improved significantly with growing expertise, outweighing our previous experience with the standard frame-based technique. ${ }^{29}$

Another important factor that might have contributed to the improvement of application accuracy was the implementation of the neurolocate device (Renishaw) into the imaging registration process. The neurolocate consists of a carbon-fiber registration module with fiducial markers that is mounted to the robotic arm for the acquisition of stereotactic imaging, for both frame-based and frameless procedure ${ }^{30}$ Cardinale et al. have previously demonstrated noninferiority of this technology in comparison to standard frame-based coregistration in a phantom study. In line with our experience, the authors also showed decreased localization error for neurolocate registration-based targeting, although in the clinical setting of stereoelectroencephalography surgery. ${ }^{30}$

Data on the accuracy of robot-assisted DBS in pediatric patients are limited. A search of the literature regarding the application of robot-assisted DBS surgery yielded 18 peer-reviewed original studies (Table 3). ${ }^{13-18,24,27,28,31-39}$ Of a total of 1006 patients reported, only 2 publications were found to have included $9(0.8 \%)$ pediatric patients altogether. The ROSA robotic system (Medtech S.A.) was used in $55.5 \%$ of the studies, followed by different versions of the neuromate device (NeuroMate, Integrated Surgical Systems; and Renishaw) in 27.8\%, the Mazor system (Mazor Robotics) in 11.1\%, and the PathFinder (Prosurgics) in 5.6\%. Only 13 of these studies reported on application accuracy of the robot-assisted technique. The overall mean application accuracy across studies was $1.46 \pm 0.14$ $\mathrm{mm}$ (range $0.48-1.7 \mathrm{~mm}$ ), and no statistically significant difference was observed between adults $(1.04 \pm 0.37 \mathrm{~mm})$ and pediatric $(1.40 \pm 0.22 \mathrm{~mm})$ patients $(\mathrm{p}=0.34)$.

The occurrence of complications was formally reported in 13 of 18 studies, with an overall $7.9 \%$ incidence of any perioperative adverse events, whereas wound site infection was the most frequent $(2.9 \%)$, followed by stimulationrelated side effects (2.4\%) and lead displacement (1.0\%). Among pediatric patients, 1 child presented with hardware infection (11.1\%) and another patient had displacement of the DBS lead (11.1\%), which had to be revised. The incidence of adverse events in the pediatric age group was 2.9-fold higher than among adult patients.

Candela et al. reported 6 children who underwent frameless robot-assisted DBS surgery for dystonia under general anesthesia. The accuracy of electrode placement in that series was $1.20 \mathrm{~mm}$, with a mean surgical time of more than 480 minutes and $16.6 \%$ lead misplacement 


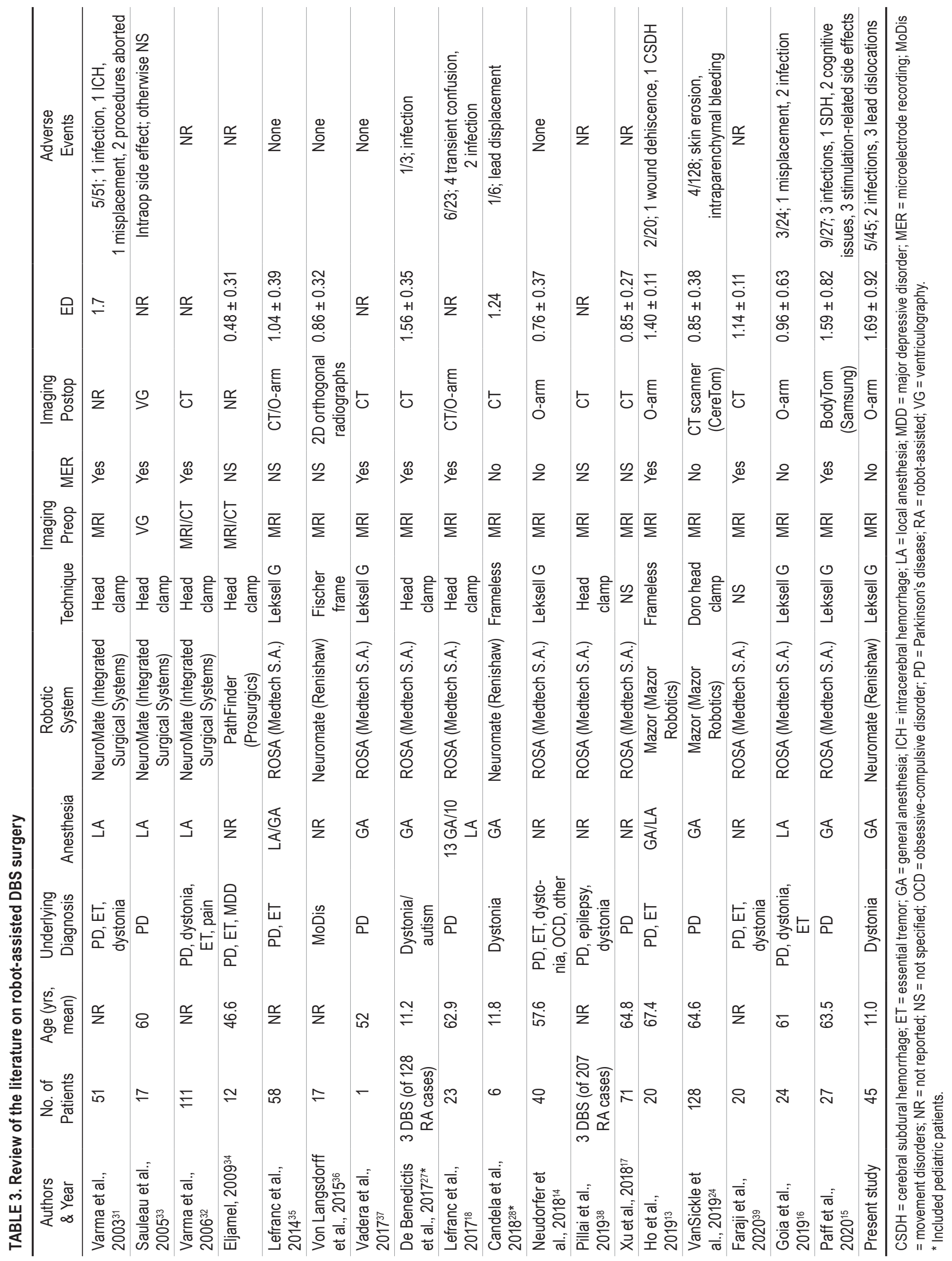


$(n=1 / 6) .{ }^{28}$ De Benedictis et al. reported their experience in 128 robot-assisted stereotactic surgeries for various indications. ${ }^{27}$ Of these, 3 (2.3\%) children underwent implantation of DBS electrodes, with a median accuracy of 1.60 $\mathrm{mm}$ and $33.3 \%(\mathrm{n}=1 / 3)$ infection rate.

As one would expect, in our case series, longer surgical times and increased EDs correlated with postoperative complications and need for revision surgery. The overall complication rate in the present cohort was $11.1 \%(5 / 45)$, which was lower than the average $22.2 \%$ complication rate reported in the literature among pediatric patients who underwent robot-assisted surgery. ${ }^{27,28}$

Our review showed that the incidence of adverse events in the pediatric age group was significantly higher than among adult patients (2.9-fold). However, the higher occurrence of postoperative hardware-related adverse events in the pediatric population compared to adults is not a particularity of robot-assisted DBS surgery..$^{40,41}$ Besides the age group, the nature and severity of dystonia per se, which is the most common indication for DBS in younger patients, poses a higher risk of perioperative adverse events. ${ }^{9,40}$

In line with previous reports, ${ }^{7,9,29}$ primary $D Y T 1$ and DYT6 genetic dystonia presented a significantly better clinical response to GPi DBS at the 1-year follow-up, as measured with dystonia severity scales, than did other genetic and acquired forms of dystonic syndromes. Importantly, we found that the proportion of life lived with dystonia was inversely correlated with functional improvement in this cohort $(\mathrm{p}=0.02)$. This finding is supported by previous reports and reinforces the concept of early surgical intervention in order to maximize functional recovery following GPi DBS.42

Although clinical improvement was to some extent demonstrated in BFMDRS, personalized functional goaldirected outcomes and improvement in upper-limb function were also evaluated using the COPM and the MA-2 scales, respectively. Previous reports from our group have shown these tools to be highly efficient in depicting individualized improvements, which would otherwise have been overlooked if solely evaluated by impairment scales following GPi DBS in children with dystonia. ${ }^{21-23}$ This reinforces the importance of the involvement of an experienced movement disorders multidisciplinary team in the process of preoperative evaluation, patient selection, and follow-up of these complex patients.

Our data provide insights into the clear impact of increasing experience and technical refinements, contributing to improvement of the application accuracy of the robot-assisted technique and to a reduction of postoperative complications in comparison to historical cohorts. ${ }^{29} \mathrm{Nev}-$ ertheless, the question regarding the most accurate, safe, and effective stereotactic method for DBS surgery is still a matter of debate..$^{14,18,43,44}$ Mirzadeh et al. recently showed in a retrospective review of 323 patients that accuracy was positively influenced by frame-based surgery $(p<0.001)$, shorter procedures $(p=0.04)$, asleep surgery $(p=0.001)$, and a head of bed angle of $0^{\circ}(\mathrm{p}=0.001){ }^{43}$

Taken together, several factors may influence the application accuracy. However, independent of the stereotactic technique used, other aspects also have a major impact on outcome. These include patient selection and preoperative screening performed by a specialized movement disorders team, surgical expertise from planning to execution and troubleshooting, perioperative medical management, and postoperative rehabilitation and follow-up. ${ }^{45}$

\section{Conclusions}

Robot-assisted stereotactic implantation of DBS electrodes in the pediatric age group is a safe and accurate surgical method. Greater accuracy and match between planned and actual lead location were present in this cohort in comparison to previous studies in which conventional stereotactic frame-based techniques were used. Several confounding factors could explain this observation, but limitations of frame registration methods and minimization of the complexity intrinsic to standard framebased stereotactic procedures are the most likely factors involved. Robotic DBS surgery and neuroradiological advances may result in further improvement in surgical targeting and, consequently, in better clinical outcome in the pediatric population.

\section{Acknowledgments}

Funding was received from the King's Health Partners Academic Health Sciences Centre, London, United Kingdom.

\section{References}

1. Albanese A, Bhatia K, Bressman SB, et al. Phenomenology and classification of dystonia: a consensus update. Mov Disord. 2013;28(7):863-873.

2. Spiegel EA, Wycis HT. Thalamotomy and pallidotomy for treatment of choreic movements. Acta Neurochir (Wien). 1952;2(3-4):417-422.

3. Coubes P, Echenne B, Roubertie A, et al. Treatment of earlyonset generalized dystonia by chronic bilateral stimulation of the internal globus pallidus. Apropos of a case. Article in French. Neurochirurgie. 1999;45(2):139-144.

4. Coubes P, Vayssiere N, El Fertit H, et al. Deep brain stimulation for dystonia. Surgical technique. Stereotact Funct Neurosurg. 2002;78(3-4):183-191.

5. Krauss JK, Yianni J, Loher TJ, Aziz TZ. Deep brain stimulation for dystonia. J Clin Neurophysiol. 2004;21(1):18-30.

6. Coubes P, Roubertie A, Vayssiere N, et al. Treatment of DYT1-generalised dystonia by stimulation of the internal globus pallidus. Lancet. 2000;355(9222):2220-2221.

7. Elkaim LM, Alotaibi NM, Sigal A, et al. Deep brain stimulation for pediatric dystonia: a meta-analysis with individual participant data. Dev Med Child Neurol. 2019;61(1):49-56.

8. Rodrigues FB, Duarte GS, Prescott D, et al. Deep brain stimulation for dystonia. Cochrane Database Syst Rev. 2019; 1:CD012405.

9. Fox MD, Alterman RL. Brain stimulation for torsion dystonia. JAMA Neurol. 2015;72(6):713-719.

10. Coubes P, Cif L, Azais M, et al. Treatment of dystonia syndrome by chronic electric stimulation of the internal globus pallidus. Article in French. Arch Pediatr. 2002;9(suppl 2): 84s-86s.

11. Krack P, Vercueil L. Review of the functional surgical treatment of dystonia. Eur J Neurol. 2001;8(5):389-399.

12. Fomenko A, Serletis D. Robotic stereotaxy in cranial neurosurgery: a qualitative systematic review. Neurosurgery. 2018; 83(4):642-650.

13. Ho AL, Pendharkar AV, Brewster R, et al. Frameless robotassisted deep brain stimulation surgery: an initial experience. Oper Neurosurg (Hagerstown). 2019;17(4):424-431. 
14. Neudorfer C, Hunsche S, Hellmich M, et al. Comparative study of robot-assisted versus conventional frame-based deep brain stimulation stereotactic neurosurgery. Stereotact Funct Neurosurg. 2018;96(5):327-334.

15. Paff M, Wang AS, Phielipp N, et al. Two-year clinical outcomes associated with robotic-assisted subthalamic lead implantation in patients with Parkinson's disease. J Robot Surg. 2020;14(4):559-565.

16. Goia A, Gilard V, Lefaucheur R, et al. Accuracy of the robotassisted procedure in deep brain stimulation. Int J Med Robot. 2019;15(6):e2032.

17. Xu F, Jin H, Yang X, et al. Improved accuracy using a modified registration method of ROSA in deep brain stimulation surgery. Neurosurg Focus. 2018;45(2):E18.

18. Lefranc M, Zouitina Y, Tir M, et al. Asleep robot-assisted surgery for the implantation of subthalamic electrodes provides the same clinical improvement and therapeutic window as awake surgery. World Neurosurg. 2017;106:602-608.

19. O'Gorman RL, Shmueli K, Ashkan K, et al. Optimal MRI methods for direct stereotactic targeting of the subthalamic nucleus and globus pallidus. Eur Radiol. 2011;21(1):130-136.

20. Burke RE, Fahn S, Marsden CD, et al. Validity and reliability of a rating scale for the primary torsion dystonias. Neurology. 1985;35(1):73-77.

21. Gimeno H, Tustin K, Lumsden D, et al. Evaluation of functional goal outcomes using the Canadian Occupational Performance Measure (COPM) following Deep Brain Stimulation (DBS) in childhood dystonia. Eur J Paediatr Neurol. 2014;18(3):308-316.

22. Gimeno H, Lumsden D, Gordon A, et al. Improvement in upper limb function in children with dystonia following deep brain stimulation. Eur J Paediatr Neurol. 2013;17(4): 353-360.

23. Gimeno H, Tustin K, Selway R, Lin JP. Beyond the BurkeFahn-Marsden Dystonia Rating Scale: deep brain stimulation in childhood secondary dystonia. Eur J Paediatr Neurol. 2012;16(5):501-508.

24. VanSickle D, Volk V, Freeman P, et al. Electrode placement accuracy in robot-assisted asleep deep brain stimulation. Ann Biomed Eng. 2019;47(5):1212-1222.

25. Moro E, LeReun C, Krauss JK, et al. Efficacy of pallidal stimulation in isolated dystonia: a systematic review and meta-analysis. Eur J Neurol. 2017;24(4):552-560.

26. Owen T, Gimeno H, Selway R, Lin JP. Cognitive function in children with primary dystonia before and after deep brain stimulation. Eur J Paediatr Neurol. 2015;19(1):48-55.

27. De Benedictis A, Trezza A, Carai A, et al. Robot-assisted procedures in pediatric neurosurgery. Neurosurg Focus. 2017;42(5):E7.

28. Candela S, Vanegas MI, Darling A, et al. Frameless robotassisted pallidal deep brain stimulation surgery in pediatric patients with movement disorders: precision and short-term clinical results. J Neurosurg Pediatr. 2018;22(4):416-425.

29. Lumsden DE, Ashmore J, Charles-Edwards G, et al. Accuracy of stimulating electrode placement in paediatric pallidal deep brain stimulation for primary and secondary dystonia. Acta Neurochir (Wien). 2013;155(5):823-836.

30. Cardinale F, Rizzi M, d'Orio P, et al. A new tool for touchfree patient registration for robot-assisted intracranial surgery: application accuracy from a phantom study and a retrospective surgical series. Neurosurg Focus. 2017;42(5):E8.

31. Varma TRK, Eldridge PR, Forster A, et al. Use of the NeuroMate stereotactic robot in a frameless mode for movement disorder surgery. Stereotact Funct Neurosurg. 2003;80(1-4): 132-135.

32. Varma TRK, Eldridge P. Use of the NeuroMate stereotactic robot in a frameless mode for functional neurosurgery. Int $J$ Med Robot. 2006;2(2):107-113.

33. Sauleau P, Raoul S, Lallement F, et al. Motor and non motor effects during intraoperative subthalamic stimulation for Parkinson's disease. J Neurol. 2005;252(4):457-464.

34. Eljamel MS. Robotic neurological surgery applications: accuracy and consistency or pure fantasy? Stereotact Funct Neurosurg. 2009;87(2):88-93.

35. Lefranc M, Capel C, Pruvot AS, et al. The impact of the reference imaging modality, registration method and intraoperative flat-panel computed tomography on the accuracy of the ROSA ${ }^{\circledR}$ stereotactic robot. Stereotact Funct Neurosurg. 2014;92(4):242-250.

36. von Langsdorff $\mathrm{D}$, Paquis $\mathrm{P}$, Fontaine $\mathrm{D}$. In vivo measurement of the frame-based application accuracy of the Neuromate neurosurgical robot. J Neurosurg. 2015;122(1):191-194.

37. Vadera S, Chan A, Lo T, et al. Frameless stereotactic robotassisted subthalamic nucleus deep brain stimulation: case report. World Neurosurg. 2017;97:762.e11-762.e14.

38. Pillai A, Ratnathankom A, Ramachandran SN, et al. Expanding the spectrum of robotic assistance in cranial neurosurgery. Oper Neurosurg (Hagerstown). 2019;17(2):164-173.

39. Faraji AH, Kokkinos V, Sweat JC, et al. Robotic-assisted stereotaxy for deep brain stimulation lead implantation in awake patients. Oper Neurosurg (Hagerstown). 2020;19(4):444-452.

40. Koy A, Bockhorn N, Kühn AA, et al. Adverse events associated with deep brain stimulation in patients with childhoodonset dystonia. Brain Stimul. 2019;12(5):1111-1120.

41. Hale AT, Monsour MA, Rolston JD, et al. Deep brain stimulation in pediatric dystonia: a systematic review. Neurosurg Rev. 2020;43(3):873-880.

42. Lumsden DE, Kaminska M, Gimeno H, et al. Proportion of life lived with dystonia inversely correlates with response to pallidal deep brain stimulation in both primary and secondary childhood dystonia. Dev Med Child Neurol. 2013;55(6): 567-574.

43. Mirzadeh Z, Chen T, Chapple KM, et al. Procedural variables influencing stereotactic accuracy and efficiency in deep brain stimulation surgery. Oper Neurosurg (Hagerstown). 2019;17(1):70-78.

44. Hariz MI, Fodstad H. Do microelectrode techniques increase accuracy or decrease risks in pallidotomy and deep brain stimulation? A critical review of the literature. Stereotact Funct Neurosurg. 1999;72(2-4):157-169.

45. Okun MS, Tagliati M, Pourfar M, et al. Management of referred deep brain stimulation failures: a retrospective analysis from 2 movement disorders centers. Arch Neurol. 2005; 62(8):1250-1255.

\section{Disclosures}

Dr. Ashkan has received education grants and honoraria from Medtronic, Abbott Medical, and Boston Scientific. Dr. Lin has received unrestricted educational grants from Medtronic.

\section{Author Contributions}

Conception and design: Furlanetti, Selway. Acquisition of data: Furlanetti, Gimeno, Ainaga, Narbad, Hasegawa. Analysis and interpretation of data: Furlanetti, Gimeno, Ainaga, Narbad, Hasegawa. Drafting the article: Furlanetti. Critically revising the article: Furlanetti, Ellenbogen, Gimeno. Reviewed submitted version of manuscript: all authors. Approved the final version of the manuscript on behalf of all authors: Furlanetti. Statistical analysis: Furlanetti. Administrative/technical/material support: Ellenbogen, Hasegawa, Lin, Ashkan, Selway. Study supervision: Furlanetti, Ellenbogen, Lin, Ashkan, Selway.

\section{Correspondence}

Luciano Furlanetti: King's College Hospital NHS Foundation Trust, Denmark Hill, London, United Kingdom. luciano.furlanetti@nhs.net. 